\title{
MINERAL-SURFACTANT INTERACTIONS FOR MINIMUM REAGENTS PRECIPITATION AND ADSORPTION FOR IMPROVED OIL RECOVERY
}

\section{TECHNICAL PROGRESS REPORT}

\author{
Reporting Period Start Date: $\quad 10 / 01 / 2005$ \\ Reporting Period End Date: 03/31/2006 \\ Principle Author: \\ Prof. P. Somasundaran \\ Date Report Issued: \\ April 30, 2006 \\ DOE Award Number: \\ DE-FC26-03NT15413 \\ Principal \\ Prof. P. Somasundaran \\ Investigator
}

\section{Submitting Organization}

Office of Projects and Grants

Columbia University in the City of New York

1210 Amsterdam Avenue, Mail Code 2205

Room 254 Engineering Terrace

New York, NY 10027

Contracting Officer's

Sue Mehlhoff

Representative

U.S. Department of Energy,

National Petroleum Technology Office

One West Third Street, Suit 1400

Tulsa, Oklahoma 74101-3519 


\section{DISCLAIMER}

This report was prepared as an account of work sponsored by an agency of the United States Government. Neither the United States Government nor any agency thereof, or any of their employees, makes any warranty, express or implied, or assumes any legal liability or responsibility for the accuracy, completeness, or usefulness of any information, apparatus, product, or process disclosed, or represents that its use would not infringe privately owned rights. Reference herein to any specific commercial product, process, or service by trade name, trademark, manufacturer, or otherwise does not necessarily constitute or imply its endorsement, recommendation, or favoring by the United States Government or any agency thereof. The views and opinions of authors expressed herein do not necessarily state or reflect those of the United States Government or any agency thereof. 


\begin{abstract}
During this reporting period, further fundamental studies were conducted to understand the mechanism of the interactions between surfactants and minerals with the aim of minimizing chemical loss by adsorption. The effects of $\mathrm{pH}$ and mixing ratio on the chemical loss by adsorption were investigated. Some preliminary modeling work has been done towards the aim of developing a guide book to design optimal polymer/surfactant formula based on the understanding of adsorption and orientation of surfactants and their aggregates at solid/liquid interfaces.
\end{abstract}

The study of adsorption of mixed system of n-dodecyl- $\beta$-D-maltoside (DM) and dodecyl sulfonate $\left(\mathrm{C}_{12} \mathrm{SO}_{3} \mathrm{Na}\right)$ was continued during this period. Based on the adsorption results, the effects of $\mathrm{pH}$ and mixing ratio on reagent loss were quantitatively evaluated. Adsorption of dodecyl maltoside showed a maximum at certain mixing ratio at low $\mathrm{pH}(3 \sim 5)$, while adsorption of dodecyl maltoside steadily decreased with the increase in $\mathrm{C}_{12} \mathrm{SO}_{3} \mathrm{Na}$.

Analytical ultracentrifuge technique was employed to study the micellization of $\mathrm{DM} / \mathrm{C}_{12} \mathrm{SO}_{3} \mathrm{Na}$ mixtures. Compositional changes of the aggregates were observed the mixing ratio of the components. Surfactant mixture micellization affects the conformation and orientation of adsorption layer at mineral/water interface and thus the wettability and as a result, the oil release efficiency of the chemical flooding processes.

A preliminary term, Reagent Loss Index (RLI), has been proposed to represent the adsorption of all the surfactants in a standardized framework for the development of the models. Previously reported adsorption data have been analyzed using the theoretical framework for the preparation of a guidebook to help optimization of chemical combinations and selection of reagent scheme for enhanced oil recovery. 


\section{TABLE OF CONTENTS}

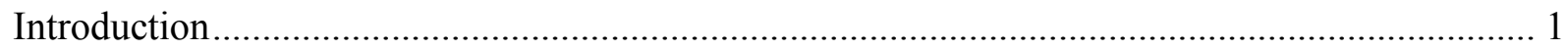

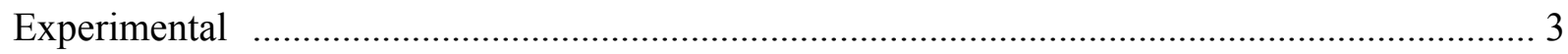

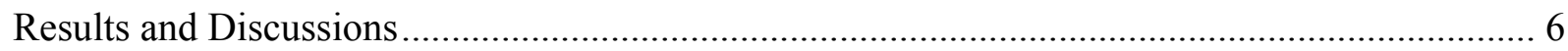

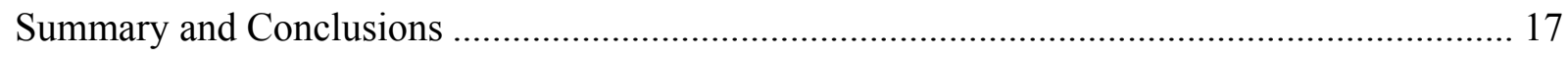

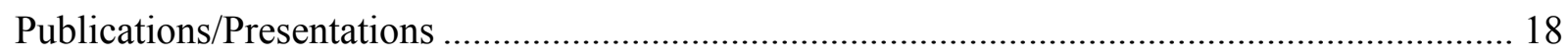

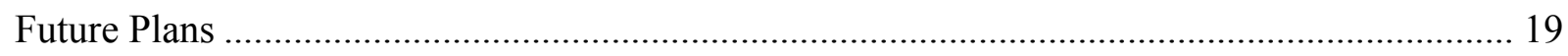

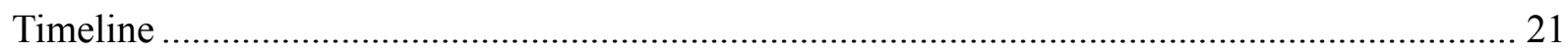




\section{LIST OF FIGURES AND TABLES}

Figure 1. Molecular structures of n-Dodecyl- $\beta$-D-maltoside and Sodium dodecylsulfonate

Figure 2. Effect of mixing ratio on the adsorption of n-dodecyl- $\beta$-D-maltoside (DM) from its mixtures with anionic $\mathrm{C}_{12} \mathrm{SO}_{3} \mathrm{Na}$ on alumina, at $\mathrm{pH} 7$ and $0.03 \mathrm{M}$ I.S.

Figure 3. Effect of mixing ratio on the adsorption of $\mathrm{C}_{12} \mathrm{SO}_{3} \mathrm{Na}$ from its mixtures with n-dodecyl- $\beta$-D-maltoside (DM) on alumina, at pH 7 and 0.03M I.S.

Figure 4. Effect of mixing ratio on the total adsorption of $\mathrm{C}_{12} \mathrm{SO}_{3} \mathrm{Na}$ and n-dodecyl- $\beta$-Dmaltoside (DM) on alumina, at $\mathrm{pH} 7$ and 0.03M I.S.

Figure 5. adsorption of dodecyl maltoside as a function of mixture ratio at varied $\mathrm{pH}$.

Figure 6. Density of DM solution as a function of concentration.

Figure 7. Density of dodecyl Sulfonate solution as a function of concentration.

Figure 8. Density of DTAC solution as a function of concentration.

Figure 9. Distribution of sedimentation coefficient of $\mathrm{DM} / \mathrm{C}_{12} \mathrm{SO}_{3} \mathrm{Na}$ system at $10 \mathrm{mM}$.

Figure 10. Distribution of sedimentation coefficient of DM/ $\mathrm{C}_{12} \mathrm{SO}_{3} \mathrm{Na}$ system at $50 \mathrm{mM}$.

Table1. Partial specific volume of three types of surfactants

Table2. Parameters of dodecyl maltoside and dodecyl sulfonate

Table3. Typical ranges of Reagent Loss Index and examples. 


\section{INTRODUCTION}

The recovery of residual oil from domestic oil reservoirs is often hampered by the loss of surfactants due to adsorption and precipitation in the reservoirs. This loss is a major problem in surfactant/polymer flooding. The goal of this project is to conduct a systematic investigation on the interactions between polymers and surfactants in bulk fluids and at mineral/fluid interfaces in enhanced oil recovery systems and therefore, to develop a model to predict the reagent loss. Polymers and surfactants can interact with each other to form aggregates or complexes in solutions and at solid/liquid interfaces. Such interactions can have drastic effects on the performance of oil recovery processes. Therefore understanding of the mechanisms of this aggregation is a major aim of this study.

During the previous period, we reported on polymer/surfactant interactions in terms of solution properties. Various combinations of three different surfactants and one polymer were studied using surface tensiometry and analytical ultracentrifuge. Polymer/surfactant complexation was observed in certain mixtures systems depending on the structure of the polymers and surfactants. Equilibrium surface tension results showed that the surface activity of the surfactant solution was reduced due to the formation of complexes. The presence of the polymer also reduced the adsorption of surfactant on the mineral under certain conditions.

In this period, we continued to investigate the adsorption of surfactant mixtures of dodecyl maltoside $(\mathrm{DM})$ and dodecyl sulfonate $\left(\mathrm{C}_{12} \mathrm{SO}_{3} \mathrm{Na}\right)$ on minerals in order to quantitatively evaluate the effects of surfactant mixing ratio. At $\mathrm{pH} 7$, adsorption of each surfactant depends on the ratio in the bulk solution, while the total adsorption remains roughly constant. The adsorption results depict the effect of $\mathrm{pH}$ and mixing ratio on the surfactant adsorption. In addition, solution behavior of $\mathrm{DM} / \mathrm{C}_{12} \mathrm{SO}_{3} \mathrm{Na}$ mixture was further investigated by analytical ultracentrifugation in 
order to determine the nature of surfactant interactions in the bulk solution. Based on the analysis of the above results, optimal formulations were selected. A preliminary term, Reagent Loss Index (RLI), is proposed to evaluate the adsorption of all the surfactant in a standardized framework for the development of the models. Previously reported adsorption data have been analyzed using the theoretical framework for the preparation of a guidebook. This in turn, will help the optimization of chemical combinations and selection of surfactant/polymer systems for different reservoir mineral environments. 


\section{EXPERIMENTAL}

\section{MATERIALS}

\section{Surfactants}

Several typical ionic and nonionic surfactants were selected for this study. During this period, anionic sodium dodecylsulfonate $\left(\mathrm{C}_{12} \mathrm{SO}_{3} \mathrm{Na}\right)$ of $\geq 99.0$ purity purchased from TCI Chemicals, Japan and non-ionic sugar-based surfactant, n-alkyl- $\beta$-D-maltoside ( $>95 \%$ purity by TLC), was purchased from Calbiochem.

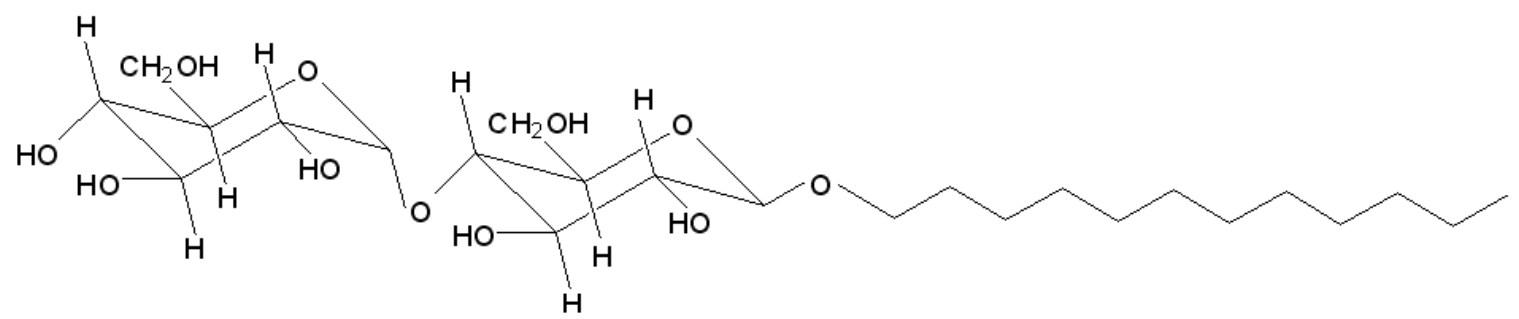

N-dodecyl- $\beta$-D-maltoside (DM)<smiles>CCCCCCCCCCCCS(=O)(=O)[O-]</smiles>

Sodium Dodecyl Sulfonate

Figure 1 Molecular structures of n-Dodecyl- $\beta$-D-maltoside and Sodium dodecylsulfonate

\section{Mineral Samples:}

Solid substrate used during the current period was alumina AKP-50 obtained from Sumitomo. It has a mean diameter of $0.2 \mu \mathrm{m}$ and the BET specific surface area of $10.8 \mathrm{~m}^{2} / \mathrm{g}$ using nitrogen/helium with a Quantasorb system. The isoelectric point (iep) of it was determined to be 8.9 . 


\section{Other Reagents:}

$\mathrm{HCl}$ and $\mathrm{NaOH}$, used for $\mathrm{pH}$ adjustment, are of A.C.S. grade certified (purity $>99.9 \%$ ), and have been purchased from Fisher Scientific Co. To study the salt effect on surface tension, micellization and adsorption, $\mathrm{NaCl}, \mathrm{CaCl}_{2}, \mathrm{FeCl}_{2}, \mathrm{AlCl}_{3}, \mathrm{Na}_{2} \mathrm{SO}_{3}$, and $\mathrm{NaNO}_{3}$ from Fisher Scientific Co.; and sodium citrate from Amend Drug \& Chemical Company, all of A.C.S. certified, were used as received. Triple distilled water used in all the experiments, had a specific conductivity of less than $1.5 \mu \Omega^{-1}$ and was tested for the absence of organics using surface tension technique.

\section{METHODS}

\section{Adsorption experiments}

Adsorption experiments were conducted in capped $20 \mathrm{ml}$ vials. Solid samples of 2 gram of alumina were mixed with $10 \mathrm{ml}$ of triple distilled water for 2 hours at room temperature. The $\mathrm{pH}$ was adjusted as desired and then $10 \mathrm{ml}$ of the surfactant solution was added, and the samples were equilibrated further for 16 hours with $\mathrm{pH}$ adjustment. The samples were then centrifuged for $30 \mathrm{~min}$ at $5000 \mathrm{rpm}$ and the clear supernatant was pipetted out for analysis.

\section{Surface tension}

The surface tension was measured at $25 \pm 1^{\circ} \mathrm{C}$ using the Wilhelmy plate technique with a sandblasted platinum plate as the sensor coupled to a Cahn microbalance. The entire assembly was kept in a draft-free plastic cage at a temperature of $25 \pm 0.05{ }^{0} \mathrm{C}$. For each measurement, the sensor was in contact with the solution for 30 minutes to allow equilibration.

\section{Analytical Techniques}

The residual concentration of the anionic surfactant after adsorption was determined by a two-phase titration method using a cationic surfactant, dodecyltrimethylammonium chloride (DTAC), as the titrating solution. Concentration of the sugar-based surfactant after adsorption 
was determined by colorimetric method through phenol-sulfuric acid reaction. The total residual surfactant concentration in ionic/nonionic surfactant mixtures after adsorption was obtained by adding the concentrations of the individual surfactant components, which was measured by either the two-phase titration or the colorimetric method.

\section{Analytical Ultracentrifuge}

A Beckman Optima XL-1 analytical ultracentrifuge with scanning optics and an interference system was employed to perform sedimentation velocity experiments. The interference optical system provides total concentration by measuring the refractive index difference between the sample cell and the reference cell at each radial position as indicated by the vertical displacement of a set of evenly spaced horizontal fringe. The running condition was set at a motor speed $40,000 \mathrm{rpm}$, and the temperature at $25^{\circ} \mathrm{C}$. Software Sedfit developed by Peter Shuck was used to analyze the sedimentation data.

\section{Density Measurement}

To obtain the specific volume of surfactant micelles, the density of surfactant solution was determined using a density meter, Anton Paar, DMA 5000.

\section{Ultrafiltration}

All ultrafiltration tests were done at room temperature $\left(22.2^{\circ} \mathrm{C}\right)$ using Amicon, YM-3, membranes, which were specified to exclude molecules with molecular weights greater than 3000. The filtration was carried out using an Amicon model 8050 filter at a $380 \mathrm{mmHg}$ nitrogen pressure. The YM-3 membrane was used to separate dodecyl maltoside and sodium dodecyl sulfonate monomers from micellar solutions. 


\section{RESULTS AND DISCUSSIONS}

\section{1) Adsorption of mixed n-dodecyl- $\beta$-D-maltoside and dodecylsulfonate on alumina: mixture}

ratio effects.

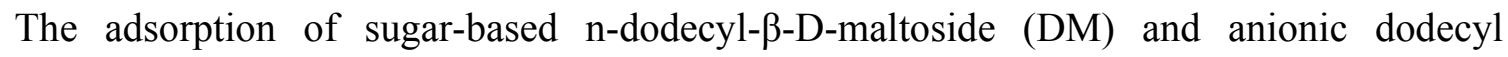
sulfonate $\left(\mathrm{C}_{12} \mathrm{SO}_{3} \mathrm{Na}\right)$ mixtures was investigated in the presence of $0.03 \mathrm{M} \mathrm{NaCl}$ at $\mathrm{pH}$. The results obtained are shown in Figures 2 and 3. It was observed that saturation adsorption of DM decreases with increase in dodecyl sulfonate, which suggests competition for adsorption sites by the sulfonate. The mixtures reach adsorption plateau at higher concentrations with increased sulfonate molar fraction due to their higher critical micelle concentration (CMC). The difference in plateau adsorption density of each surfactant corresponds to the $\mathrm{DM} /$ sulfonate ratio ranging from 3:1 to 1:3. These effects are significant for enhanced oil recovery because it will be beneficial to arrive at saturated adsorption at lowest surfactant concentrations.

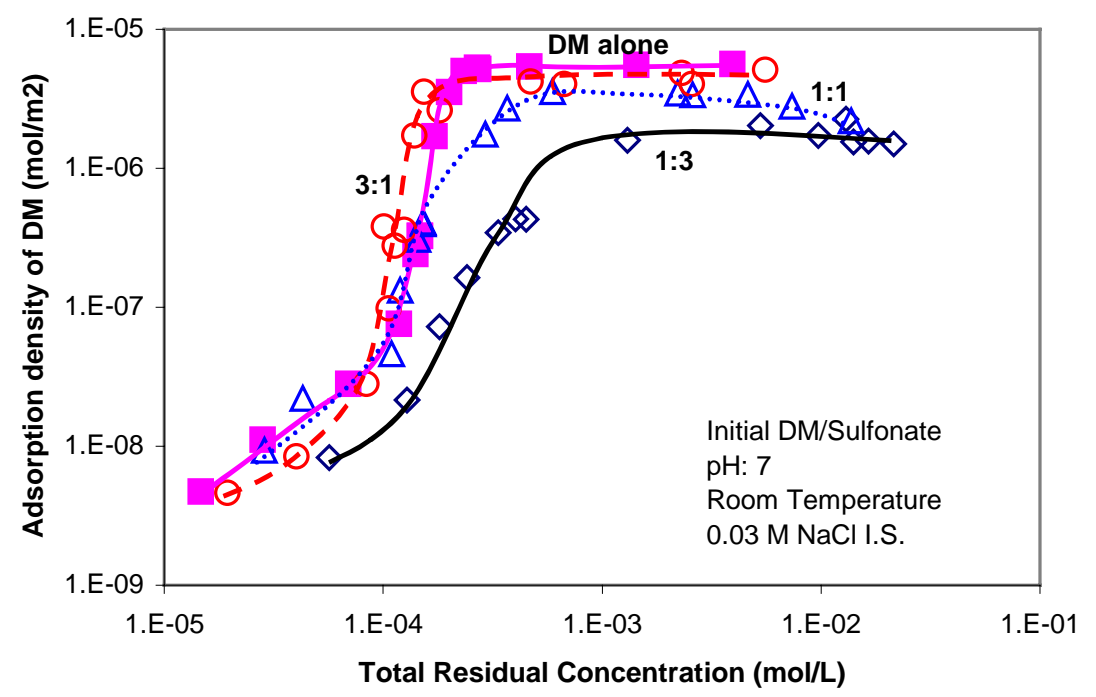

Figure 2. Effect of mixing ratio on the adsorption of n-dodecyl- $\beta$-D-maltoside (DM) from its mixtures with anionic $\mathrm{C}_{12} \mathrm{SO}_{3} \mathrm{Na}$ on alumina, at $\mathrm{pH} 7$ and $0.03 \mathrm{M}$ I.S. 


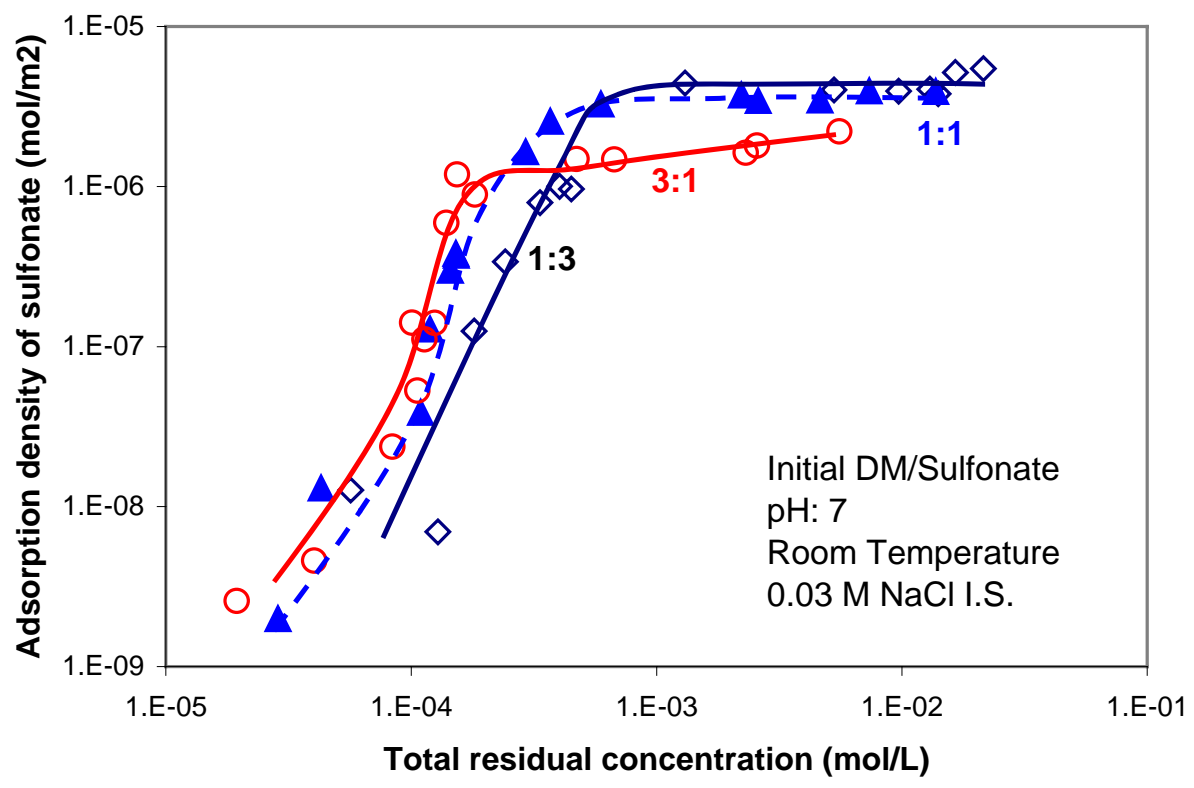

\section{Figure 3. Effect of mixing ratio on the adsorption of $\mathrm{C}_{12} \mathrm{SO}_{3} \mathrm{Na}$ from its mixtures with $\mathrm{n}$ -

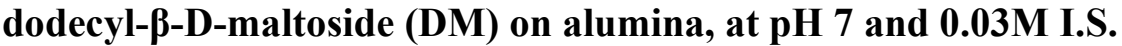

The saturation adsorption of $\mathrm{C}_{12} \mathrm{SO}_{3} \mathrm{Na}$ on alumina also decreases along with the increase in dodecyl maltoside ratio in the mixture. However, it was noticed that the sum of saturation adsorption density of dodecyl maltoside and $\mathrm{C}_{12} \mathrm{SO}_{3} \mathrm{Na}$ remains fairly constant with mixing ratio (Figure 4). This can be related to the fact that the total adsorption area on the solid surface is fixed. In addition, this observation may also indicate the relative value of interactions among surfactants and mineral surface. The adhesive interaction between the two surfactants and alumina are almost same at $\mathrm{pH} 7$, so the ratio of the surfactants in the adsorbed layer depends also on the ratio of the surfactants in the bulk. Our conclusion is in good agreement with the results reported previously, namely $\mathrm{pH} 7$ appears to be a critical point for adsorption of dodecyl maltoside and dodecyl sulfonate mixture on alumina. Below pH 7 dodecyl sulfonate is more attracted to the solid surface than dodecyl maltoside, whereas dodecyl maltoside seems to adsorb 
more above $\mathrm{pH}$ 7. Quantification of the interaction among surfactants and minerals is necessary for the modeling of adsorption of surfactant mixtures on minerals.

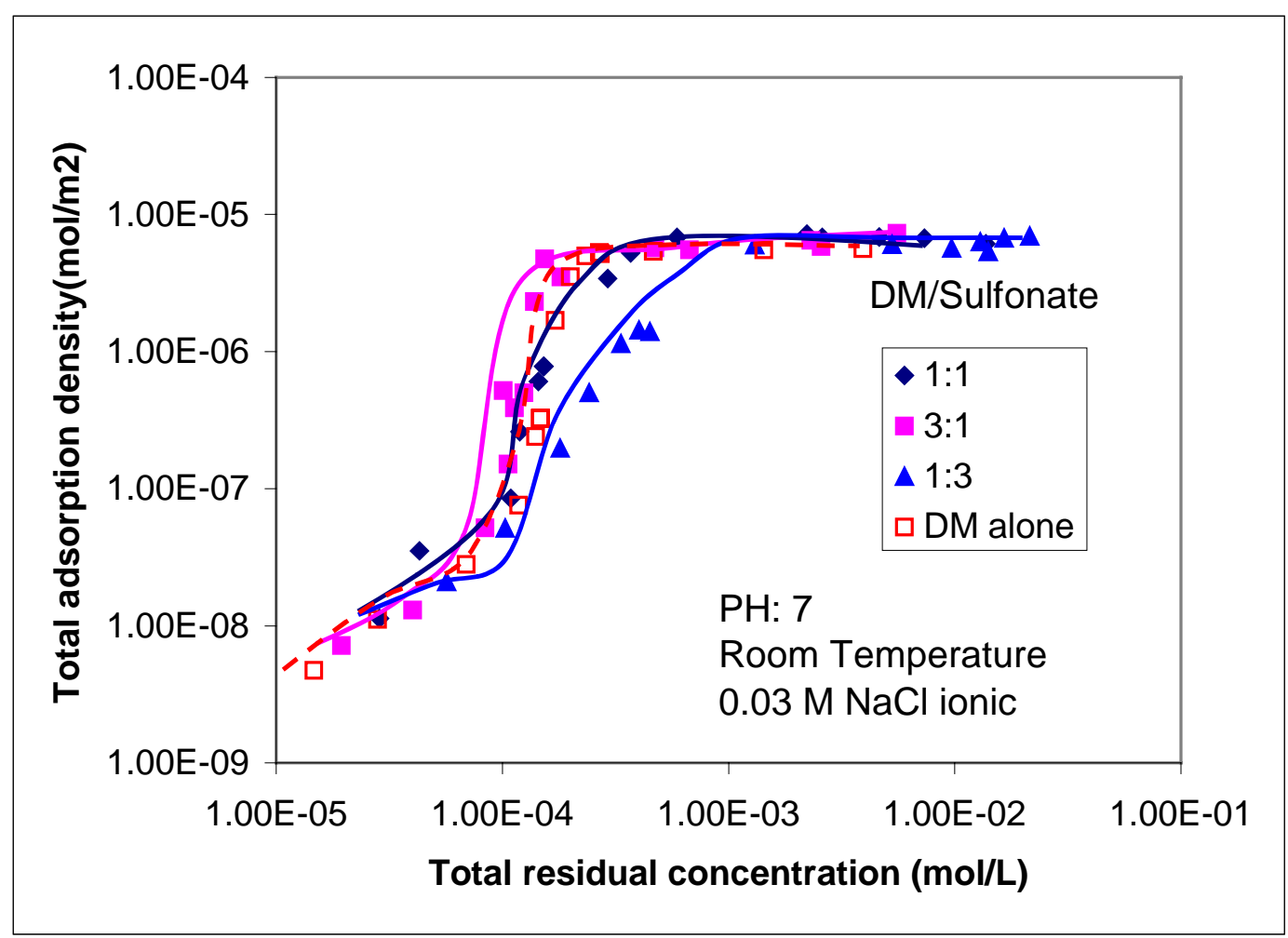

Figure 4. Effect of mixing ratio on the total adsorption of $\mathrm{C}_{12} \mathrm{SO}_{3} \mathrm{Na}$ and n-dodecyl- $\beta$-Dmaltoside (DM) on alumina, at pH 7 and $0.03 M$ I.S.

To identify the synergism or antagonism between DM and sulfonate, additional adsorption tests were carried out as a function of mixing ratio at different $\mathrm{pH}$. The initial concentration of DM was fixed at $5 \times 10-3 \mathrm{~mol} / \mathrm{L}$. The three curves at low $\mathrm{pH}$ in figure 5 exhibit two stages with a linear increase followed by a decrease. As discussed above, DM does not adsorb much on alumina below pH 7 without the sulfonate. Sulfonate can therefore be considered as an activating agent for DM adsorption in the first stage due to the chain-chain interactions. In the second stage, however, DM adsorption decreases, since the total number of available adsorption sites on the solid surface is limited, causing competitive interaction to occur. The curve of $\mathrm{pH} 10$ exhibits continuous decrease, showing no enhancement of DM adsorption. 
Interestingly, the maximum adsorption point shifts to left with decrease in $\mathrm{pH}$, with good linearity in each stage suggesting a quantitative relationship between DM adsorption and surfactant mixing ratio. This information will be prove helpful while developing a model for synergism and antagonism.

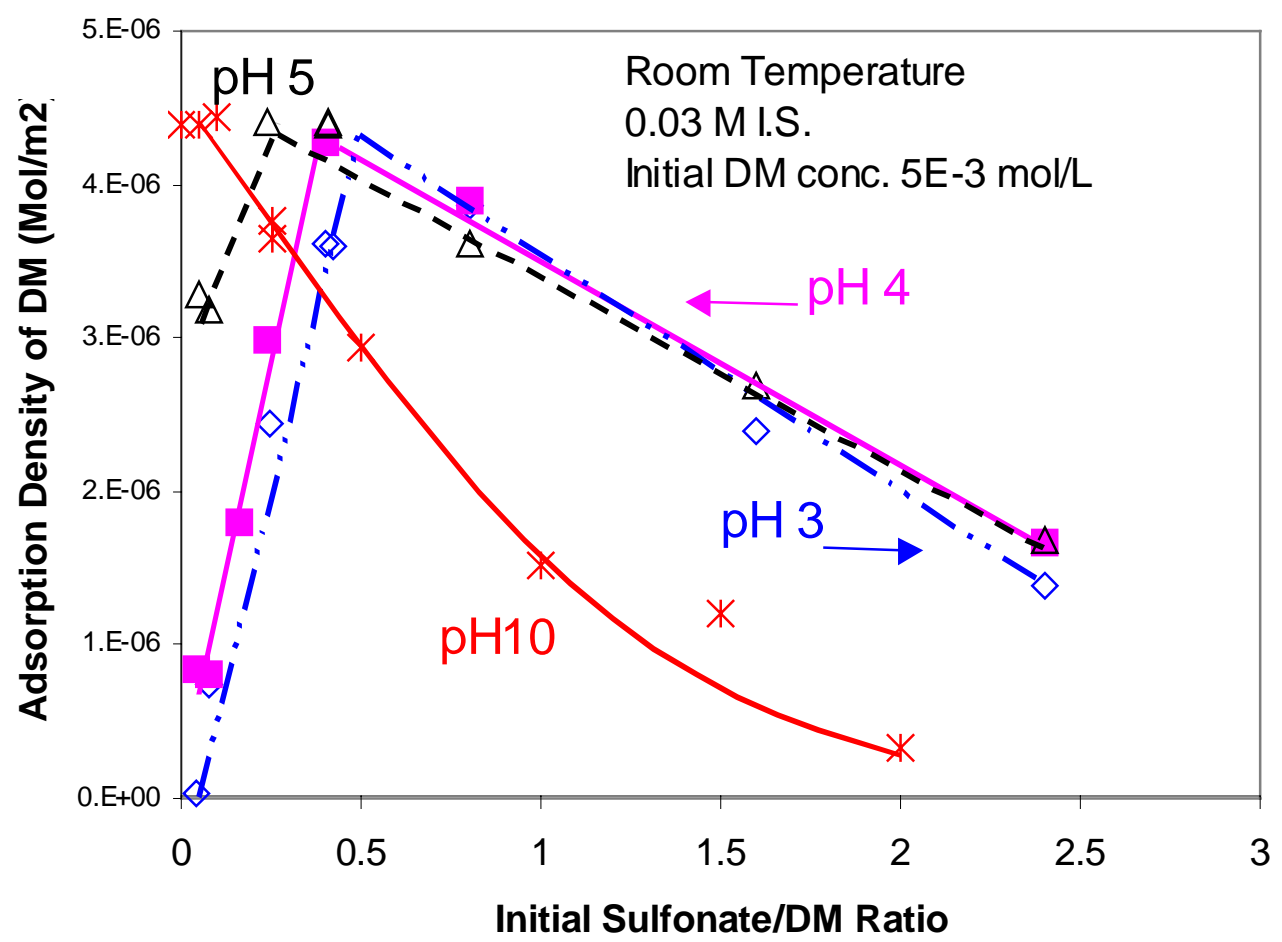

Figure 5 adsorption of dodecyl maltoside as a function of mixture ratio at varied $\mathrm{pH}$

2). Micellization of mixed n-Dodecyl- $\beta$-D-maltoside and dodecyl sulfonate studied by Analytical Ultracentrifuge (AUC)

Analytical ultracentrifuge technique was employed to obtain further information about the surfactant micelles, particularly in terms of aggregate number, micelle size and shape as a function of mixing ratio. The experiments were run at $40000 \mathrm{rpm}$ and $25.0{ }^{\circ} \mathrm{C}$. The sedimentation velocity curves were obtained during 15 hours of scanning at an interval of 2 minutes. Afterwards, the results were analyzed using software Sedfit. The distribution of sedimentation 
coefficient for various systems was obtained by fitting the velocity curves. DM forms much larger micelles in comparison to dodecyl sulfonate; this is attributed to the electrostatic repulsion among dodecyl sulfonate head groups that limits the micellar growth.

Data on Partial specific volume of surfactant micelle, the volume of unit weight of micelle, is essential for calculating further information such as the sedimentation coefficient and the micelle mass, in analytical ultracentrifuge data analysis. The partial specific volume, $\bar{v}$, can be obtained empirically from the density gradient. The first method yields the partial specific volume using the following equation:

$$
\bar{v}=\frac{1}{\rho_{0}}\left(1-\frac{d \rho}{d C}\right)
$$

where $\mathrm{C}$ is the surfactant volumeric concentration in grams per milliliter and $\rho$ and $\rho_{0}$ are the densities of the solution and solvent, respectively. The solution densities of the surfactants studied above in terms of the adsorption were determined using a density meter, having a six digital accuracy. The variation of densities of DM, dodecyl sulfonate and DTAC with surfactant concentration is shown in figures 6-8, respectively. Nonionic dodecyl maltoside and anionic dodecyl sulfonate show a positive slope, suggesting a partial specific volume smaller than that of the solvent, while cationic dodecyltrimethylammonium chloride (DATC) shows a negative slope. The partial specific volumes were calculated using the equation above and the values are listed in the Table 1. The values of partial specific volume thus obtained have been utilized in the treatment of the analytical ultracentrifuge data. 


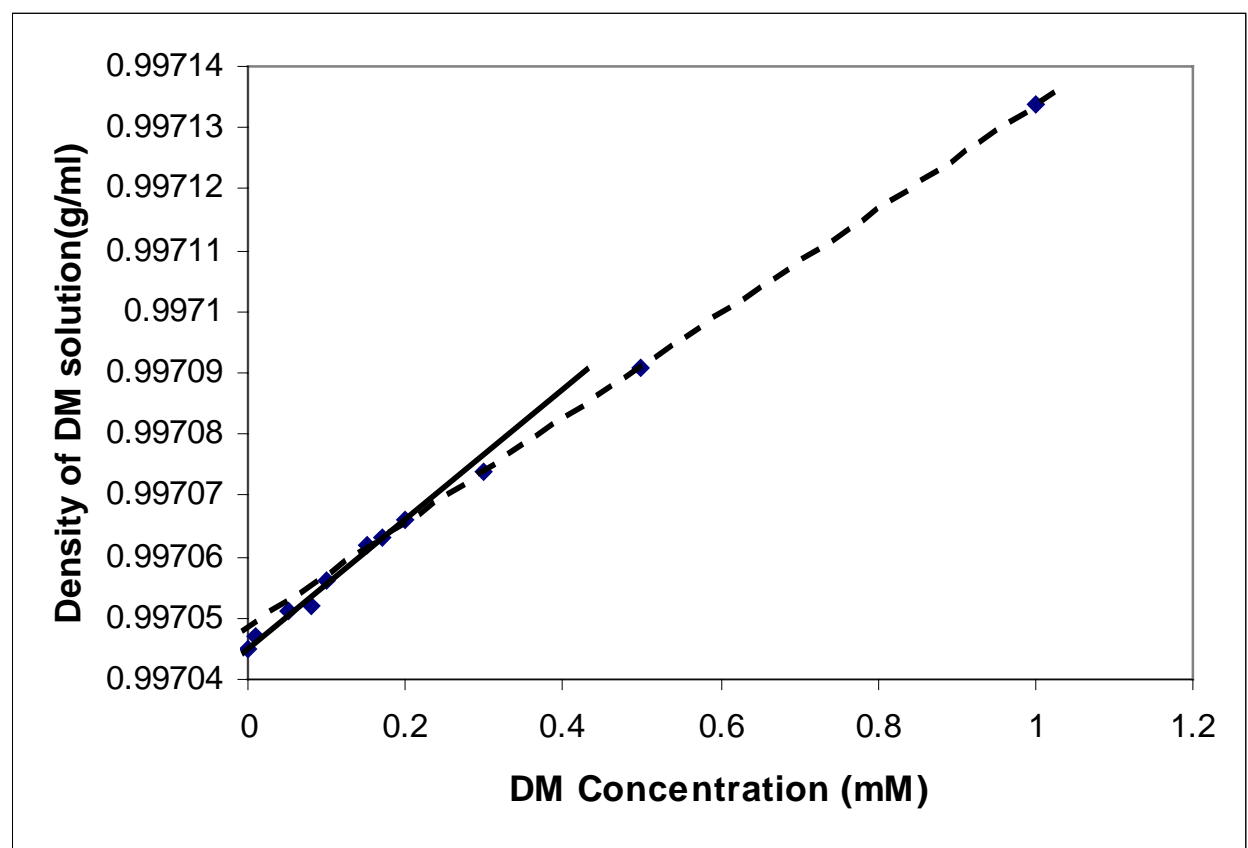

Figure 6 Density of DM solution as a function of concentration

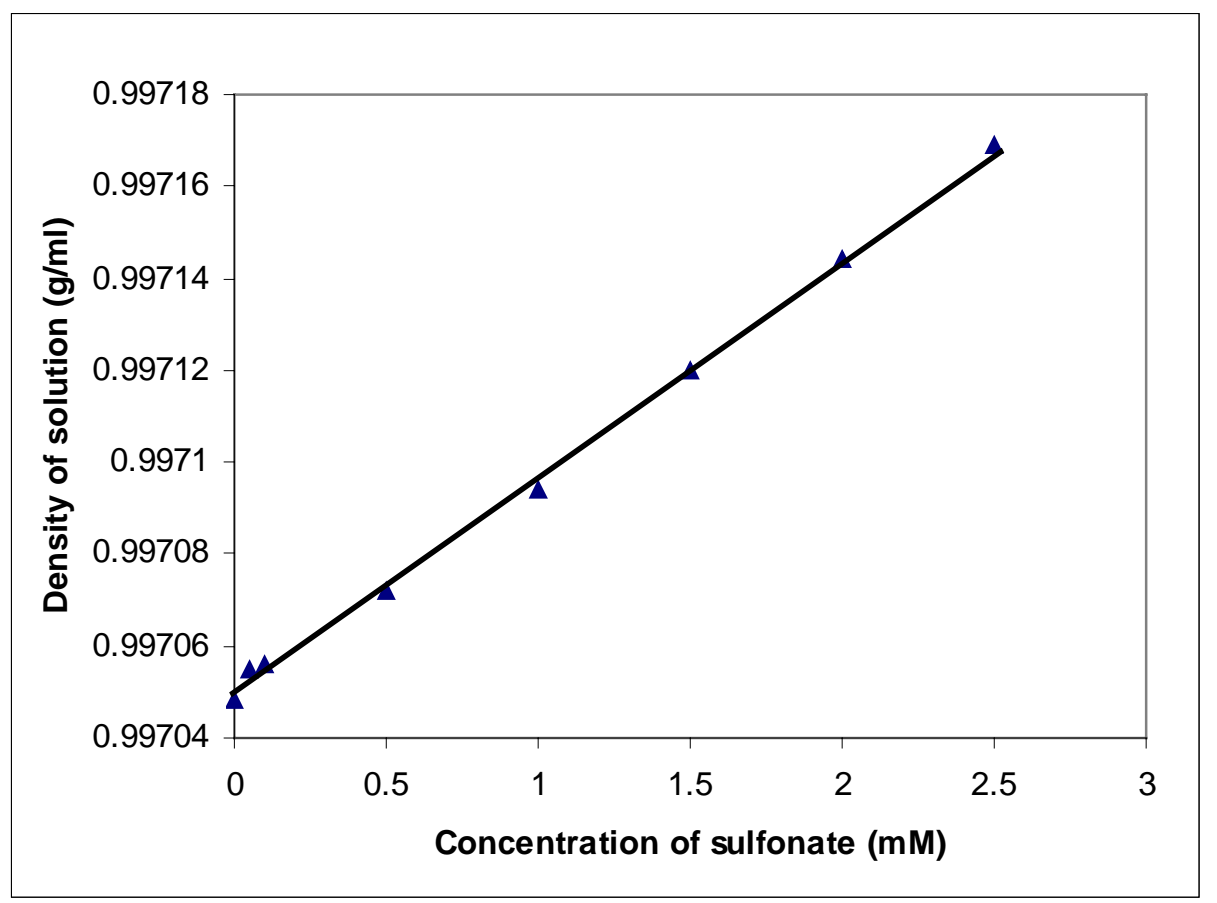

Figure 7 Density of Dodecyl Sulfonate solution as a function of concentration 


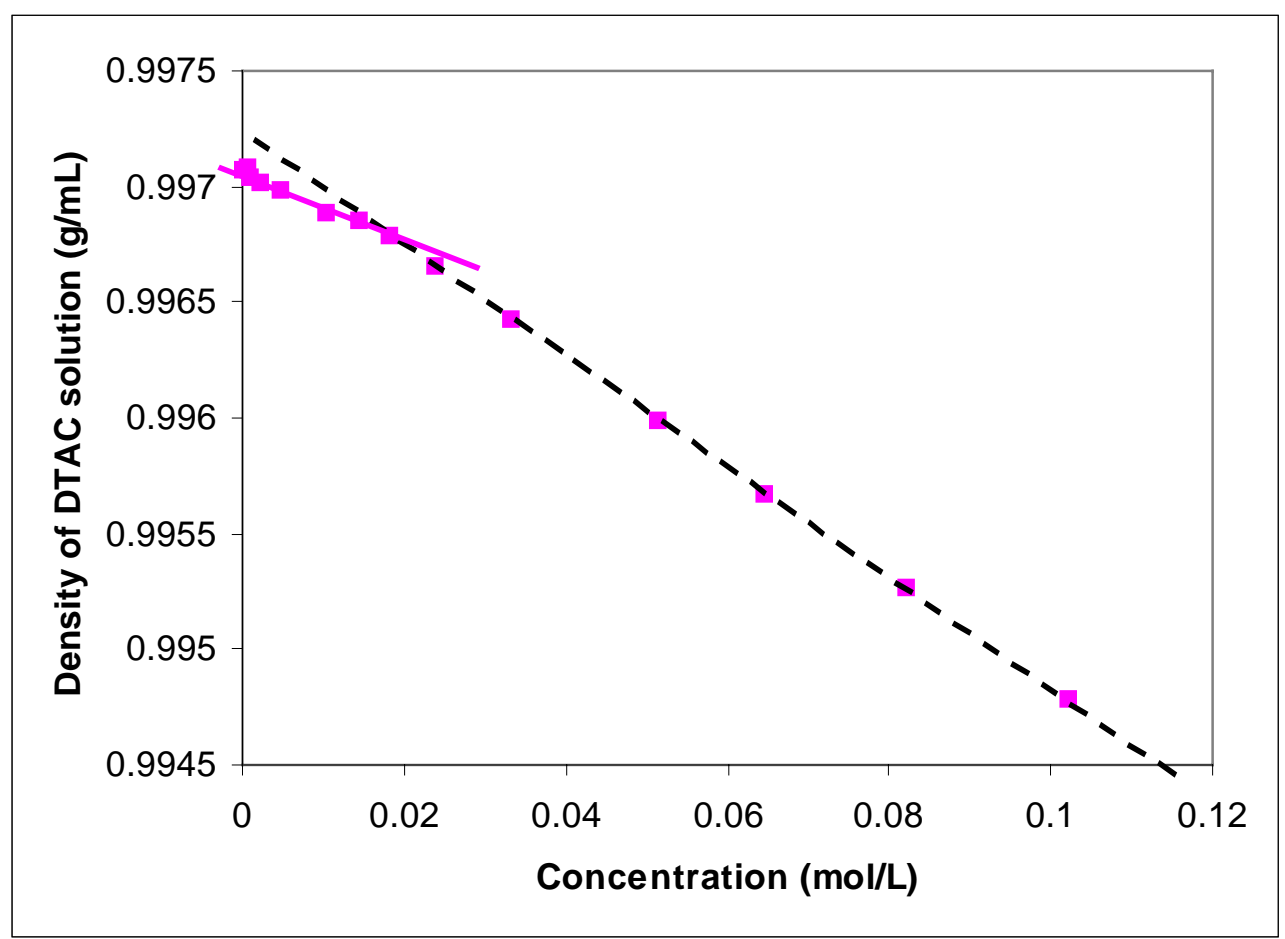

Figure 8 Density of DTAC solution as a function of concentration

Table1. Partial specific volume of three types of surfactants

\begin{tabular}{|c|c|c|}
\hline S. No. & Surfactant & $\begin{array}{c}\text { Partial Specific } \\
\text { Volume }\end{array}$ \\
\hline 1. & DM & 0.833 \\
2. & $\mathrm{C}_{12} \mathrm{SO}_{3} \mathrm{Na}$ & 0.826 \\
3. & DTAC & 1.08 \\
\hline
\end{tabular}

Information about micelles of $\mathrm{DM} / \mathrm{C}_{12} \mathrm{SO}_{3} \mathrm{Na}$ system obtained from the analytical ultracentrifuge is summarized in figures 9 and 10. Interestingly, despite the fact that these two surfactants have very close partial specific volumes, they form very different micelles. 


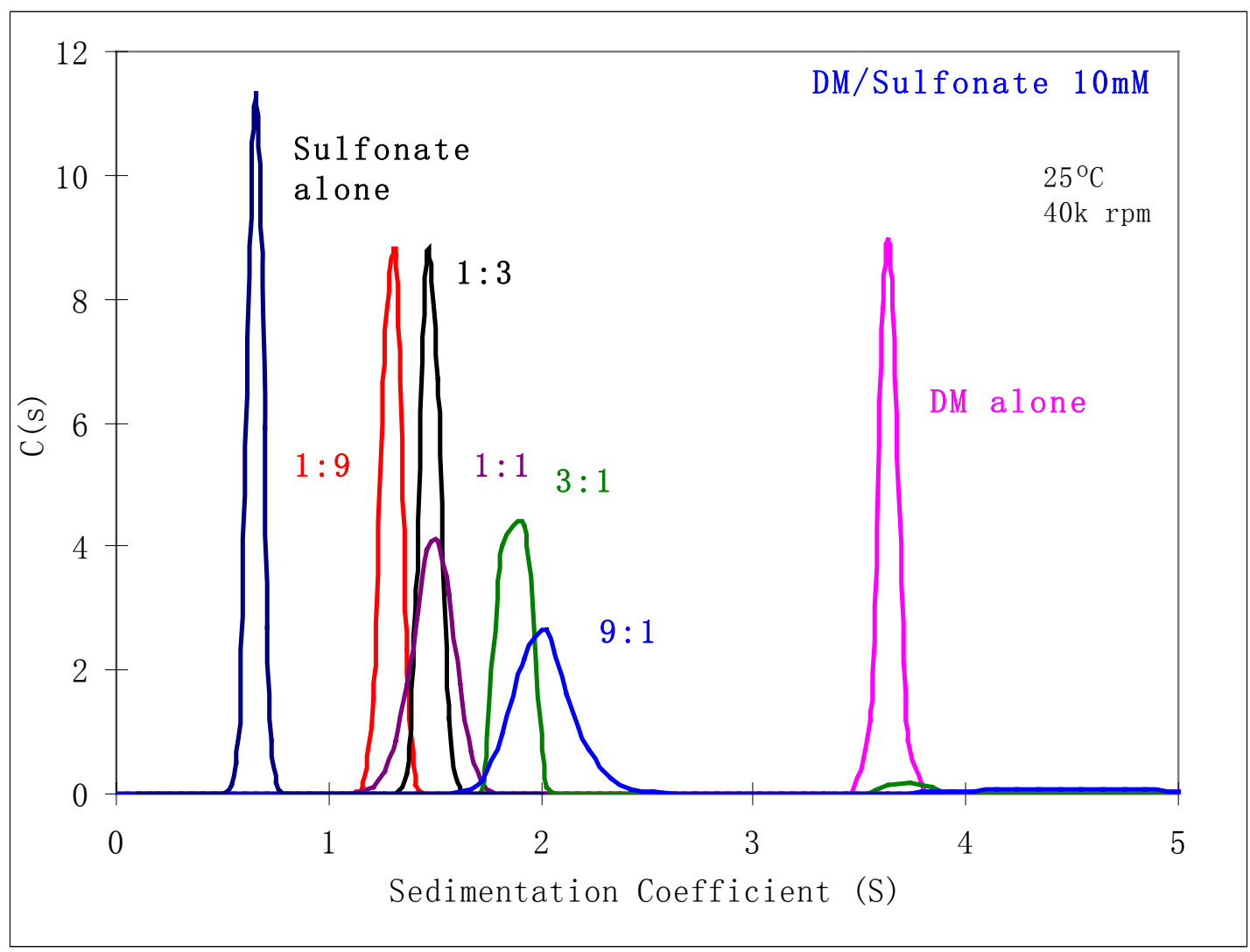

Figure 9 Distribution of sedimentation coefficient of $\mathrm{DM} / \mathrm{C}_{12} \mathrm{SO}_{3} \mathrm{Na}$ system at $10 \mathrm{mM}$.

The peaks of $\mathrm{C}_{12} \mathrm{SO}_{3} \mathrm{Na}$ and dodecyl maltoside show narrow distribution with the sedimentation coefficient positions at 0.65 and 3.68 respectively. The higher sedimentation coefficient value of DM micelles indicates that size of DM micelle is much larger than that of $\mathrm{C}_{12} \mathrm{SO}_{3} \mathrm{Na}$ micelles. The sedimentation coefficient peaks of mixtures of $\mathrm{DM} / \mathrm{C}_{12} \mathrm{SO}_{3} \mathrm{Na}$ of ratios from 9:1 to 1:9 are distributed between 1 and 3. This indicates that geometry of mixed micelles is different from both $\mathrm{DM}$ and $\mathrm{C}_{12} \mathrm{SO}_{3} \mathrm{Na}$. It can also be observed that the sedimentation coefficient peaks of mixed micelles are closer to the peak of $\mathrm{C}_{12} \mathrm{SO}_{3} \mathrm{Na}$ than that of DM suggesting that electrostatic repulsion dominates the micellization process of this surfactant mixture. 
The peaks at $50 \mathrm{mM}$ concentration are very different from those obtained at $10 \mathrm{mM}$ concentration (Figure 10). All three mixed micelle peaks are crowded in the range close to the position of $\mathrm{C}_{12} \mathrm{SO}_{3} \mathrm{Na}$ alone, due to very high electrostatic repulsion among surfactant molecules and micelles.

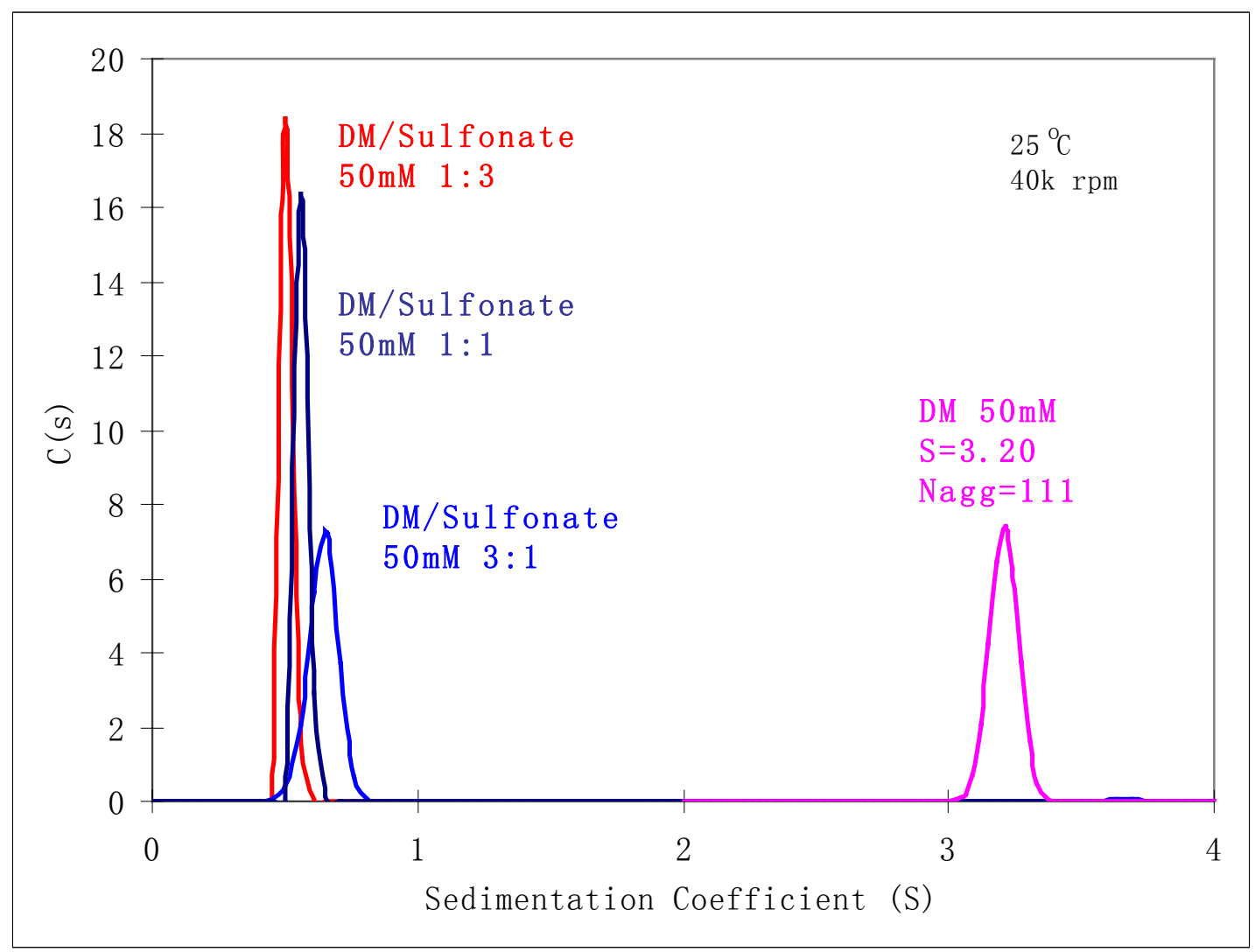

Figure 10 Distribution of sedimentation coefficient of $\mathrm{DM} / \mathrm{C}_{12} \mathrm{SO}_{3} \mathrm{Na}$ system at $50 \mathrm{mM}$.

The information obtained from analytical ultracentrifuge, including size, shape and distribution, reveals the interaction between different surfactant components and suggests the mechanism of surfactant mixture adsorption on minerals and will be utilized to help develop a predictive model. 


\section{3).Preliminary theoretical framework of modeling of reagents loss in enhanced oil recovery.}

In order to predict the adsorption of surfactants on minerals, researchers have proposed different models most of which often focus on fitting the adsorption curve in the range around CMC. In enhanced oil recovery, however, the key aspect that controls chemical reagent loss is the adsorption behavior of surfactants and their mixtures in the saturation ranges, because surfactants are often used at the concentration range above CMC in order to get enough surface activity.

Based on the analysis of previously reported adsorption results and data obtained in past, a new term entitled, Reagent Loss Index (RLI), is proposed to evaluate the performance of any surfactant in a standardized framework. The Reagent Loss Index is defined as the ratio between the actual loss due to adsorption and precipitation and the theoretical maximum adsorption $\mathrm{Ads}_{\mathrm{o}}$, when a complete double layer form at the solid surface.

$$
R L I=\frac{\text { Actual Loss }}{A d s_{0}}
$$

The theoretical maximum adsorption, $\mathrm{Ads}_{\mathrm{o}}$, can be easily calculated when the area per surfactant molecule can be obtained. The area per molecule of dodecyl maltoside and dodecyl sulfonate was calculated based on the surface tension results (Figure 9 in $3^{\text {rd }}$ semiannual report, April 2005) and the values obtained are listed in the Table 2.

Table2. Parameters of dodecyl maltoside and dodecyl sulfonate

\begin{tabular}{|c|c|c|c|}
\hline & $\begin{array}{c}\text { Area per molecule } \\
\left(\mathbf{n m}^{2}\right)\end{array}$ & $\begin{array}{c}\text { Ads } \\
\text { 0 }\end{array}$ & $\begin{array}{c}\text { Reagent Loss Index } \\
\text { (RLI) at pH 7 on } \\
\text { alumina }\end{array}$ \\
\hline DM & $\mathbf{0 . 4 6}$ & $\mathbf{7 . 2 \times 1 0 ^ { - 6 }}$ & $\mathbf{0 . 7 6}$ \\
\hline C12SO3NA & $\mathbf{0 . 5 8}$ & $\mathbf{5 . 7 \times 1 0 ^ { - 6 }}$ & $\mathbf{0 . 9 5}$ \\
\hline
\end{tabular}

As shown in table 3, the previous adsorption results are categorized into 6 different RLI ranges. 
Table3. Typical ranges of Reagent Loss Index and examples.

\begin{tabular}{|c|c|c|}
\hline $\begin{array}{l}\text { Reagent Loss Index } \\
\text { (RLI) range }\end{array}$ & Phenomenon & Cases \\
\hline 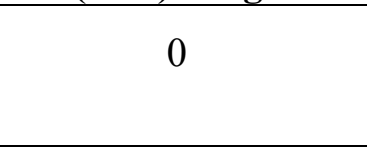 & No adsorption & $\begin{array}{l}\text { Ionic surfactant alone on } \\
\text { solid surfaces with the same } \\
\text { charge }\end{array}$ \\
\hline$\sim 0$ & Little adsorption & Dodecyl maltoside on silica \\
\hline $0 \sim 0.5$ & Medium adsorption & $\begin{array}{c}\text { DM on alumina in } \mathrm{pH} \text { range } \\
3 \sim 6\end{array}$ \\
\hline $0.5 \sim 1$ & Strong adsorption & $\begin{array}{l}\text { DM on alumina in } \mathrm{pH} \text { range } \\
7 \sim 10\end{array}$ \\
\hline $1 \sim$ & Enhanced adsorption & $\begin{array}{c}\text { Ionic surfactant on highly } \\
\text { oppositely charged mineral } \\
\text { surface }\end{array}$ \\
\hline$>1$ & Precipitation & $\begin{array}{l}\text { Sodium dodecyl sulfate on } \\
\text { gypsum and limstone. }\end{array}$ \\
\hline
\end{tabular}




\section{SUMMARY AND CONCLUSIONS}

During this research period, adsorption of surfactant mixtures on minerals and micellization of mixed surfactants were investigated in order to elucidate the mechanisms of interactions from the point of view of molecular structures. Some preliminary work has been done towards the aim of modeling for practical enhanced oil recovery.

The effect of mixing ratio on adsorption of dodecyl maltoside/ $\mathrm{C}_{12} \mathrm{SO}_{3} \mathrm{Na}$ mixture on alumina was investigated at various $\mathrm{pH}$ levels. At $\mathrm{pH} 7$, the adsorption of each component in plateau range was found to be dependant on its ratio in the bulk solution, however, the total adsorption remained constant. Interestingly, an adsorption maximum of dodecyl maltoside was found at certain $\mathrm{C}_{12} \mathrm{SO}_{3} \mathrm{Na}$ ratio at low $\mathrm{pH}$, while it decreases steadily in the presence of $\mathrm{C}_{12} \mathrm{SO}_{3} \mathrm{Na}$ at $\mathrm{pH} 10$. The balance between electrostatic attraction and hydrogen bonding, which is assumed to be the driving force of adsorption for dodecyl sulfoante and dodecyl maltoside on alumina, controls the adsorption of this mixed surfactant system on alumina.

To further understand the adsorption behavior and quantitatively predict the trend, analytical ultracentrifuge was employed to obtain information on $\mathrm{DM} / \mathrm{C}_{12} \mathrm{SO}_{3} \mathrm{Na}$ system. The results obtained suggest that electrostatic force dominates the micellization process of surfactant mixtures, even in the system containing only $10 \%$ of $\mathrm{C}_{12} \mathrm{SO}_{3} \mathrm{Na}$. Electrostatic force becomes more dominant at higher surfactant concentrations.

A new term, Reagent Loss Index (RLI), is proposed to represent the adsorption behavior of different surfactant and solids in a uniform theoretical framework. Some previous adsorption and precipitation results are categorized in six different RLI ranges. This work will be continued in the next the development of guidebook for enhanced oil recovery. 


\section{Publications and Presentations}

1) Shaohua $\mathrm{Lu}$ and $\mathrm{P}$. Somasundaran, Analytical ultracentrifuge study of micellization of surfactant mixtures, Oral Presentation The 231st ACS National Meeting, Atlanta, GA, March 2630,2006

2) Shaohua Lu and P. Somasundaran, Synergy Among Surfactants in Solution and on Particles in Suspensions. Industrial Advisory Board meeting in University of Florida, Feb 21 2006, (Received Best Poster Reward).

3) Shaohua Lu and P. Somasundaran, Rock Wettability Control and Chemical Loss Reduction, 2006 AAPG Rocky Mountain Section Annual Meeting (June 11-13, 2006) (submitted).

4) Shaohua Lu and P. Somasundaran, Solution behavior of nonionic/anionic surfactant mixtures, The 16th International Symposium on Surfactants in Solution KOREA, June 2006 (accepted) 


\section{FUTURE PLANS}

For task 1c:

- Investigate interactions of minerals with surfactant-polymers mixtures and at different mixing ratios, in order to select chemicals with minimum adsorption. Simultaneously, determine changing in wettability and interfacial potential change of minerals due to surfactants/polymers adsorption. The results will be analyzed to elucidate the mechanism of adsorption of polymer on minerals. Neutron reflection studies will be performed in NIST, as the proposal has been approved. Adsorption data of various chemicals will be used to screen formulations for optimum performances.

For task 2:

* The effects of dissolved species (multivalent and univalent ions, such as $\mathrm{Na}^{+}, \mathrm{Ca}^{2+}, \mathrm{Mg}^{2+}$, $\mathrm{Fe}^{2+}, \mathrm{SO}_{4}{ }^{2-}$ etc) on the adsorption of selected surfactant / polymer systems on minerals under various conditions will be determined. The effect of polymers on the adsorption of surfactant on various types of minerals such as alumina will also be investigated. Adsorption, abstraction and precipitation studies will be conducted to determine optimum formulation to minimize the loss of chemicals due to precipitation.

\section{For task 3:}

Selection of optimal formulations under simulated reservoir conditions: selected experiments will be conducted in the lab under representative reservoir conditions $(\mathrm{pH}$, salinity and temperature) to test the validity of the optimal condition. Phase diagram of mixtures of representative oil and optimal formulations, possibly mixtures of surfactants and polymers, will be examined to determine the possibility of formation of emulsions in 
the presence of dissolved multivalent ions from minerals.

For task 4:

Develop models to obtain a quantitative understanding of the interactions between minerals and surfactants/polymers, the precipitation of chemical reagents due to the dissolution of multivalent ions from the minerals, and the performance of the formulations under reservoir conditions. Based on the models, a guidebook containing optimally desirable chemical combinations will be collected to facilitate the evaluation of formulations of the surfactant/polymers for different reservoir mineral environments in terms of several key parameters.

Note: We are behind in timeline due to a period without a postdoc and due to the part time appointment of the new postdoc. It may be necessary to request a no-fund extension of the contract. 
DOE Timeline: Mineral-Surfactant Interactions for Minimum Reagent Loss in IOR

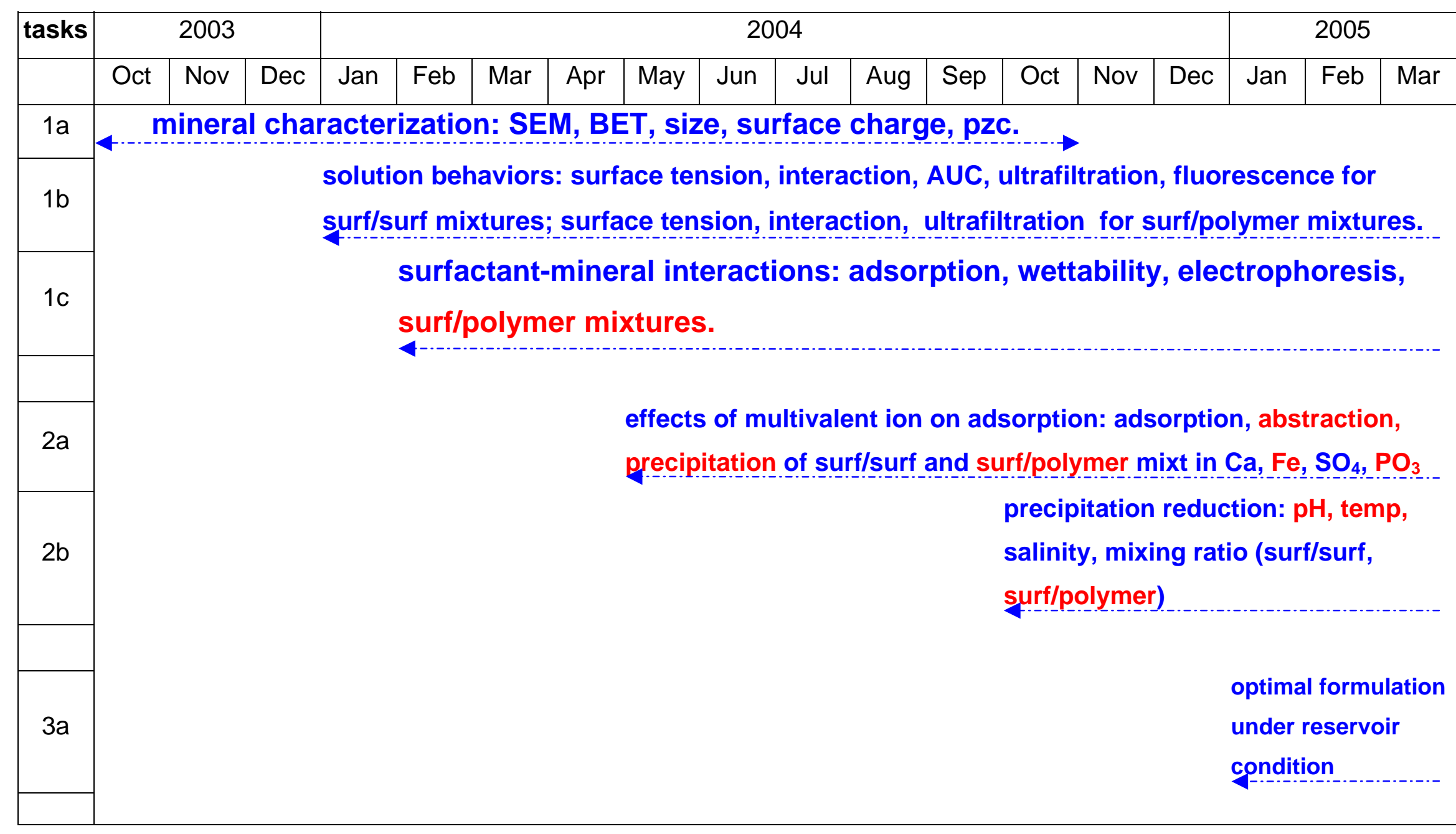

Tasks fulfilled in blue

Tasks planned in red 


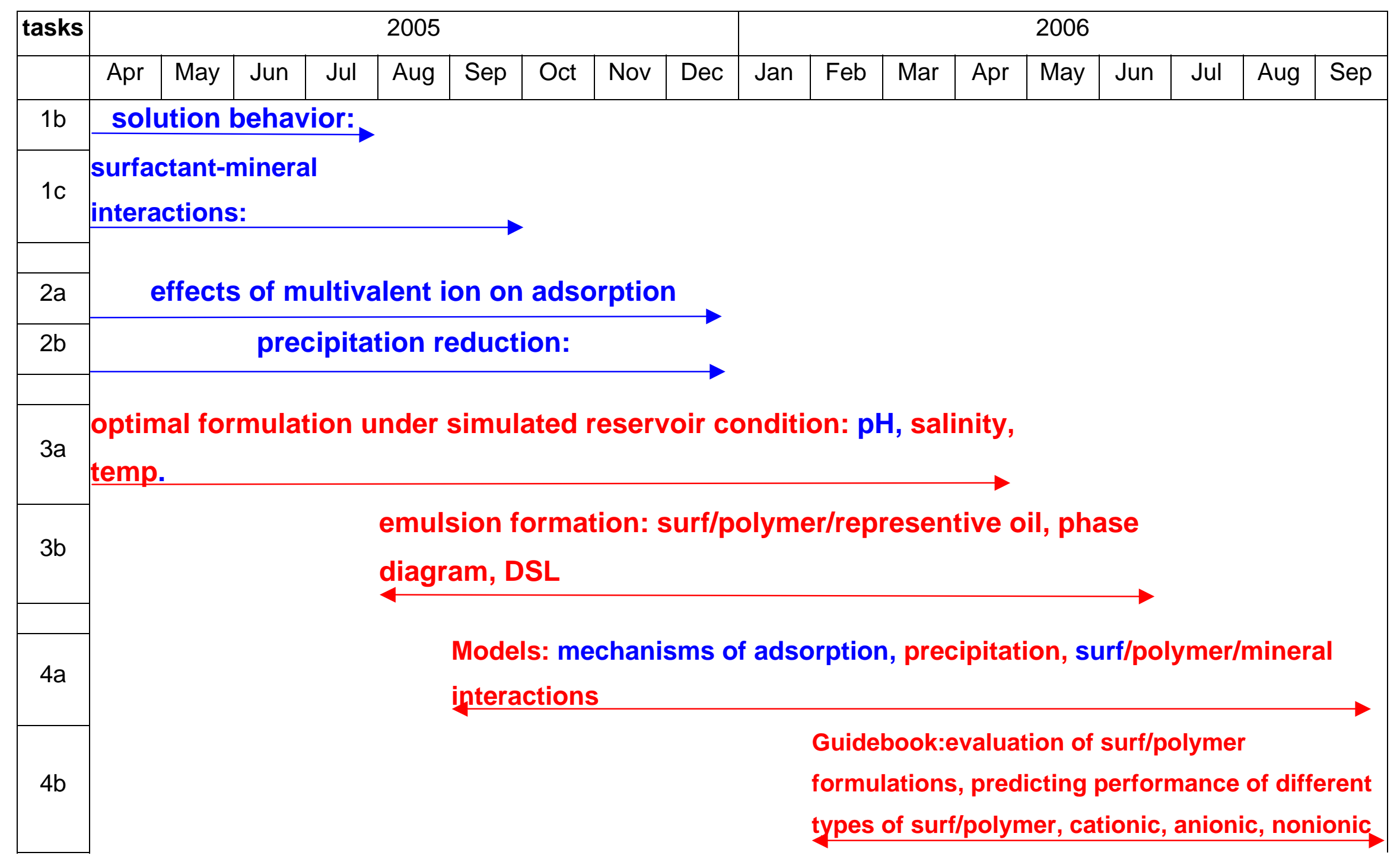

Tasks fulfilled in blue Tasks planned in red 